\title{
Substance use and its predictors among undergraduate medical students of Addis Ababa University in Ethiopia
}

\author{
Wakgari Deressa ${ }^{1 *}$ and Aklilu Azazh²
}

\begin{abstract}
Background: Substance use remains high among Ethiopian youth and young adolescents particularly in high schools and colleges. The use of alcohol, khat and tobacco by college and university students can be harmful; leading to decreased academic performance, increased risk of contracting HIV and other sexually transmitted diseases. However, the magnitude of substance use and the factors associated with it has not been investigated among medical students in the country. This study was conducted to determine the prevalence of substance use and identify factors that influenced the behavior among undergraduate medical students of Addis Ababa University in Ethiopia.
\end{abstract}

Methods: A cross-sectional study using a pre-tested structured self-administered quantitative questionnaire was conducted in June 2009 among 622 medical students (Year I to Internship program) at the School of Medicine. The data were entered into Epi Info version 6.04d and analyzed using SPSS version 15 software program. Descriptive statistics were used for data summarization and presentation. Differences in proportions were compared for significance using Chi Square test, with significance level set at $p<0.05$. Multivariate logistic regression analyses were used to assess the magnitude of associations between substance use and sociodemographic and behavioral correlates.

Results: In the last 12 months, alcohol was consumed by $22 \%$ (25\% males vs. $14 \%$ females, $p=0.002$ ) and khat use was reported by $7 \%$ ( $9 \%$ males vs. $1.5 \%$ females, $p<0.001$ ) of the students. About $9 \%$ of the respondents $(10.6 \%$ males vs. $4.6 \%$ females, $p=0.014)$ reported ever use of cigarette smoking, and $1.8 \%$ were found to be current smokers. Using multiple logistic regression models, being male was strongly associated with alcohol use in the last 12 months (adjusted $\mathrm{OR}=2.14,95 \% \mathrm{Cl}=1.22-3.76$ ). Students whose friends currently consume alcohol were more likely to consume alcohol (adjusted $\mathrm{OR}=2.47,95 \% \mathrm{Cl}=1.50-4.08$ ) and whose friends' use tobacco more likely to smoke (adjusted $\mathrm{OR}=3.89,95 \% \mathrm{Cl}=1.83-8.30$ ). Khat use within the past 12 months was strongly and positively associated with alcohol consumption (adjusted $\mathrm{OR}=15.11,95 \% \mathrm{Cl}=4.24-53.91$ ). Similarly, ever use of cigarette was also significantly associated with alcohol consumption (adjusted $\mathrm{OR}=8.65,95 \% \mathrm{Cl}=3.48-21.50$ ).

Conclusions: Concordant use of alcohol, khat and tobacco is observed and exposure to friends' use of substances is often implicated. Alcohol consumption or khat use has been significantly associated with tobacco use. While the findings of this study suggest that substance use among the medical students was not alarming, but its trend increased among students from Year I to Internship program. The university must be vigilant in monitoring and educating the students about the consequences of substance use.

\footnotetext{
* Correspondence: deressaw@yahoo.com

'Department of Epidemiology and Biostatistics, School of Public Health,

College of Health Sciences, Addis Ababa University, Ethiopia

Full list of author information is available at the end of the article
} 


\section{Background}

Use of substances such as alcohol, khat leaves (Catha edulis) and tobacco has become one of the rising major public health and socio-economic problems worldwide. Recent trends indicate that the use of substances have dramatically increased particularly in developing countries [1]. Alcohol, especially in high doses, or when combined with khat or tobacco, continues to claim the lives of many people. It is estimated that $9 \%$ of the global population aged 12 or older are classified with dependence on psychoactive substances such as alcohol [2]. Heavy consumption of khat is associated with euphoria, hyperactivity, anorexia, insomnia, lethargy and depression. In addition, the combined use of alcohol and khat could increase sexual risky behavior contributing to the spread of human immunodeficiency virus (HIV) infection [2].

The problem of substance use has historically been linked to health professionals due to their close proximity to the drugs. This problem highly impairs the practice of medicine with reasonable skill and safety to patients because of their illness or dependence on drugs [3-5]. Tobacco consumption has been the main risk factor for chronic diseases such as cancers, chronic lung disease, diabetes and cardiovascular diseases, however; its use has become a growing concern among college students in many parts of the world [6]. Furthermore, the use of drugs and alcohol among medical students has become a growing concern $[7,8]$. Studies also suggest differentials in alcohol and other drug use between adolescents and young adults with regard to sexual identity among undergraduate students [9].

With 74 million people in 2007, Ethiopia is the second most populous nation after Nigeria in sub-Saharan Africa with an annual population growth rate estimated at $2.7 \%$ [10]. Children under the age of 15 years comprise about $45 \%$ of the total population. Several studies indicate that substance use among Ethiopian adolescents is considerably rising [11-14]. Nowadays, alcohol and khat are widely consumed among high school and college students in Ethiopia [11,13-15]. There is a strong link between khat chewing and excessive alcohol consumption, and it is believed to be one of the factors associated with unprotected risky sexual behavior, predisposing the youth for HIV infection and transmission [14,16,17]. Studies also indicate that adolescent girls start and regularly use drugs and alcohol than boys [18].

Of the young segment of the Ethiopian population, college and university students are the most at risk of using alcohol and other drugs such as khat and tobacco. Most often stimulant medications are increasingly used by high school and college students as a means to improve academic performance. Entering the university, often leads to new opportunities, independence from family control, self-decision making, and peer-pressures to use or abuse alcohol or other drugs. It is generally acknowledged that several factors are involved in the initiation of substance use among adolescents and young adults.

The use of alcohol, khat and tobacco among adolescents can be harmful, leading to decreased academic performance, increased risk of contracting HIV and other sexually transmitted diseases, or other psychiatric disorders such as lethargy, hopelessness and insomnia [2]. Furthermore, it exposes students to legal repercussions, or jeopardizes their enrollment at the university. Substance use behaviors among medical students have important implications for the health of the general population since physicians and future physicians are important role models in terms of health related behaviors. This group of population should be identified as a crucial group for preventing substance use and the transmission of HIV [19-21].

Though alcohol consumption, khat chewing and cigarette smoking have become common practices among high school and college/university students in Ethiopia, only very few studies have assessed their magnitude and the associated factors $[11,13]$. The practice of medicine requires commitment, enthusiasm and altruism, indicating that medical students deserve special attention in relation to alcohol and other drug use. They are the ones who will be responsible for the health of the society in the future. Therefore, it is important to understand the pattern of substance use among this population group.

The objective of this study was to explore the magnitude of self-reported substance use and any association between these habits and the associated factors among undergraduate medical students. Such information provides crucial support for efforts aimed at developing a healthy lifestyle, strengthening on campus standards of conduct and for improving HIV/AIDS prevention and control programs among college and university students.

\section{Methods}

This study was carried out in June 2009 among undergraduate medical students attending from Year I to internship program at the Faculty of Medicine, Addis Ababa University, Ethiopia. The Faculty of Medicine with its specialized Tikur Anbessa teaching hospital was founded in 1964 in Addis Ababa, the capital of Ethiopia. By the time of the survey, there were 19 departments at the Faculty. In June 2009, the total number of full-time registered undergraduate medical students from Year I to internship was 800 ; of whom about $36 \%$ were females. Since its establishment, the Faculty has graduated 1890 general medical practitioners (MD) and 862 specialists [22]. The duration for the undergraduate medical training has a curriculum lasting for $51 / 2$ years 
and the postgraduate medical training lasts between 2-4 years depending on the area of specialty. The medical school admits students from all over the country and uptake into the school for undergraduate program is determined by the national criteria set by the Federal Ministry of Education based on the performance of high school leaving examinations.

The study utilized an institution-based cross-sectional study design with quantitative data collection method. The study population included all medical students (Year I to internship program) attending medical training at the Faculty of Medicine. There were no pre-medical students registered at the Faculty at the time of the study. The sample size was determined by Epi Info 2002 software package using a single proportion formula for cross-sectional survey, based on the prevalence of alcohol consumption (44\%) during the past year among university students [23]. Using $4 \%$ margin of error at $95 \%$ confidence level, the sample size required was 615 after considering $5 \%$ non-response rate. Since the number of all medical students across all batches at the Faculty was not very much larger than the desired sample size for the study, all students from Year I to internship were enrolled into the study. Students were divided into two main categories, based on their current training level: (i) pre-clinical (Year I and Year II) and (ii) clinical (Year III, Year IV and internship).

A questionnaire was developed by reviewing relevant literature and previously used standardized instruments and protocols. It contained 100 questions, most of which were closed-ended with pre-coded responses. The questions were divided into four sections: (i) socio-demographic characteristics; (ii) alcohol and drug use; (iii) khat chewing habit; and (iv) smoking status. Substance use in this study is defined as the use of alcohol, khat and/or tobacco by medical students either in lifetime, in the past 12 months or in the past month/week. The survey questionnaire was constructed and administered in English since the medium of instruction in Ethiopia particularly in high schools and Universities is in English. The questionnaire was pretested in paramedical students, and appropriate revisions were made before being used for actual data collection.

Data were collected through self-administration of the questionnaires after gathering students in the lecture halls of the Faculty and explaining the purpose of the study. After the distribution of the questionnaire, the students were oriented on the questionnaire, the type of sections and the number of questions contained in it. Finally, instructions on how to properly fill the questionnaire, particularly how to follow skip patterns, were given to the students. The questionnaires were then collected back after they were completed by the end of the session; and checked and edited for completeness.
The data were entered into Epi Info version 6.04d and transferred to SPSS version 15 (SPSS Inc, Chicago, IL, USA) software program for analysis. Data entry was done by an experienced data clerk at the School of Public Health. Data cleaning, processing, preliminary analysis and final write-up were done by the research team. Descriptive statistics such as means for continuous and proportion for categorical variables including cross-tabulations were used for data summarization. Differences in proportions were compared for significance using Chi Square test, with significance level set at $\mathrm{p}<0.05$. When the assumptions of the Chi Square test were not fulfilled, we used the Fisher exact test.

Finally, multivariate logistic regression analyses were used to identify factors associated with substance use by controlling for the effect of potential confounding variables. Alcohol, khat and tobacco intake were included in the logistic model mainly as dependent variables, while the following factors were included in the model as independent variables: gender, age, religion, source of family income, rural-urban background, medical education status, parental and friends' substance use. Adjusted odds ratios (ORs) and their 95\% confidence intervals were reported. The likelihood ratio statistic was used to test the evidence for interaction between the risk factors such as friends' and parental use of substances and the covariate gender.

This study was reviewed and approved by the Institutional Review Board of the Faculty of Medicine at Addis Ababa University. All responsible people in the Faculty were informed about this study. Participation of the students in this study was voluntary and verbal informed consent was obtained from each participant before data collection. Students were informed that questionnaires were anonymous and confidential. Names of the students were not recorded anywhere on the questionnaire and measures were taken to ensure the respect, dignity and freedom of each student participating in the study. Appropriate measures were also taken to ensure confidentiality of information both during and after data collection.

\section{Results}

The final sample included 622 undergraduate medical students with complete data out of 632 students participated in the study. Ten filled questionnaires were discarded due to data incompleteness. The response rate was $78 \%$ ( $86 \%$ pre-clinical vs. $62 \%$ clinical students) from a total of 800 registered medical students from Year I to internship program at the Faculty by the time of the survey. The main reason for non-participation was absenteeism on the day of the data collection mainly due to various clinical practices at different hospitals in Addis Ababa. 
Table 1 displays the socio-demographic characteristics of the sample by sex. The sample includes more men (68.5\%) than women, which was consistent with the

Table 1 Socio-demographic characteristics of the students by sex, June 2009

\begin{tabular}{|c|c|c|c|}
\hline \multirow[b]{2}{*}{ Characteristics } & \multicolumn{2}{|c|}{ Sex } & \multirow[b]{2}{*}{$\begin{array}{l}\text { Total, } \mathrm{n} \\
(\%)\end{array}$} \\
\hline & $\begin{array}{l}\text { Male, } \mathrm{n} \\
(\%)\end{array}$ & $\begin{array}{l}\text { Female, } \mathrm{n} \\
(\%)\end{array}$ & \\
\hline \multicolumn{4}{|l|}{ Age in years } \\
\hline $15-19$ & $148(34.7)$ & 77 (39.3) & $225(36.2)$ \\
\hline $20-24$ & $265(62.2)$ & $118(60.2)$ & $383(61.6)$ \\
\hline 25 or more & $13(3.1)$ & $1(0.5)$ & $14(2.3)$ \\
\hline \multicolumn{4}{|l|}{ Religion } \\
\hline Orthodox Christian & $264(62.0)$ & $125(63.8)$ & $389(62.5)$ \\
\hline Protestant Christian & $83(19.5)$ & $41(20.9)$ & $124(19.9)$ \\
\hline Muslim & $61(14.3)$ & $25(12.8)$ & $86(13.8)$ \\
\hline Other & $18(4.2)$ & $5(2.5)$ & $23(3.8)$ \\
\hline \multicolumn{4}{|l|}{ Marital status } \\
\hline Never married & $415(97.4)$ & $194(99.0)$ & 609 (97.9) \\
\hline Ever married/cohabiting & $11(2.6)$ & $2(1.0)$ & $13(2.1)$ \\
\hline \multicolumn{4}{|l|}{$\begin{array}{l}\text { Completed high school in Addis } \\
\text { Ababa }\end{array}$} \\
\hline Yes & $210(49.3)$ & $166(84.7)$ & $376(60.5)$ \\
\hline No & $216(50.7)$ & $30(15.3)$ & $246(39.5)$ \\
\hline \multicolumn{4}{|l|}{ Original background } \\
\hline Urban & $311(73.0)$ & $187(95.4)$ & $498(80.1)$ \\
\hline Rural & $115(27.0)$ & $9(4.6)$ & $124(19.9)$ \\
\hline \multicolumn{4}{|l|}{ Medical education status } \\
\hline Year I & $229(53.8)$ & $83(42.3)$ & $312(50.2)$ \\
\hline Year II & 89 (20.9) & $46(23.5)$ & $135(21.7)$ \\
\hline Year III & $38(8.9)$ & $31(15.8)$ & $69(11.1)$ \\
\hline Year IV & $47(11.0)$ & $34(17.3)$ & $81(13.0)$ \\
\hline Internship & $23(5.4)$ & $2(1.0)$ & $25(4.0)$ \\
\hline \multicolumn{4}{|l|}{ Mother's educational level } \\
\hline Illiterate & $173(40.6)$ & $30(15.3)$ & $203(32.6)$ \\
\hline Elementary to grade 12 & $96(22.5)$ & $36(18.4)$ & $132(21.2)$ \\
\hline $\begin{array}{l}12^{\text {th }} \text { grade complete plus } \\
\text { diploma }\end{array}$ & $113(26.5)$ & $83(42.3)$ & $196(31.5)$ \\
\hline First degree or above & $44(10.3)$ & $47(24.0)$ & $91(14.6)$ \\
\hline \multicolumn{4}{|l|}{ Father's educational level } \\
\hline Illiterate & $138(32.4)$ & $18(9.2)$ & $156(25.1)$ \\
\hline Elementary to grade 12 & 92 (21.6) & $36(18.4)$ & $128(20.6)$ \\
\hline $\begin{array}{l}12^{\text {th }} \text { grade complete plus } \\
\text { diploma }\end{array}$ & $90(21.1)$ & $50(25.5)$ & $140(22.5)$ \\
\hline First degree or above & $106(24.9)$ & $92(46.9)$ & $198(31.8)$ \\
\hline \multicolumn{4}{|l|}{ Family's main source of income } \\
\hline Government employee & $123(28.9)$ & $67(34.2)$ & $190(30.5)$ \\
\hline Business & $97(22.8)$ & $65(33.2)$ & $162(26.0)$ \\
\hline Agriculture-based & $126(29.6)$ & $8(4.1)$ & $134(21.5)$ \\
\hline NGO/private firm employee & $37(8.7)$ & $40(20.4)$ & $77(12.4)$ \\
\hline Other & $43(10.1)$ & $16(8.2)$ & $59(9.5)$ \\
\hline Total, N (\%) & $\begin{array}{c}426 \\
(68.5 \%)\end{array}$ & $196(31.5 \%)$ & $\begin{array}{l}622 \\
(100 \%)\end{array}$ \\
\hline
\end{tabular}

registrar's sex composition report of students. The overall age of the sample ranged from 18 to 39 years, with the majority (62\%) being between 20 to 24 years. About $63 \%$ and $20 \%$ of the sample were Orthodox and Protestant Christians, respectively, followed by Muslim (14\%). Only $2.1 \%$ of the respondents were either ever married or cohabited.

With regard to the area of original residence, most students $(80 \%)$ were from urban background and the remaining (20\%) from rural areas (Table 1). About 95\% of the females, compared with $73 \%$ of males, were from urban backgrounds. Similarly, about $61 \%$ of the students completed their high school education in Addis Ababa and the remaining (40\%) finished their education in high schools all over around the country out of the capital. With regard to their medical training status, about $72 \%$ of them were pre-clinical (Year I and II), while $28 \%$ were clinical students (Year III and IV) including internship program. The number of medical students by the training years showed a recent massive enrollment of students into the medical school.

The parental education of the respondents revealed that $33 \%$ of the mothers and $25 \%$ of the fathers were reported to be illiterate, with only $15 \%$ of the mothers and $32 \%$ of the fathers with first degree or above (Table 1). Government employment (31\%), business (26\%), agriculturebased (22\%), and NGO/private firm employee (12\%) were the main reported source of parents' income. Students were also asked about their monthly pocket money. Although $23 \%$ of the students did not report their estimated monthly pocket money; of those who revealed it, $45 \%$ reported Birr 100-299 and 39\% indicated Birr 300 or more. The average monthly income reported was Birr 246 (228 for males and 292 for females), and the overall median was Birr 100. The average monthly pocket money reported by female students was much higher than that reported by males.

Table 2 displays lifetime and past-year/month/week prevalence of alcohol use by sex. Lifetime use of alcohol was reported by about $31 \%(95 \% \mathrm{CI}=28-35)$ of the respondents and $22 \%$ reported drinking alcohol in the past year. There were significant differences between males and females with respect to alcohol use behavior; for example, about $35 \%$ of males reported lifetime alcohol consumption compared to $22 \%$ female students ( $\mathrm{p}=$ 0.001). A greater number of males than females reported alcohol use over the past-year and past-month, showing a statistically significant difference $(\mathrm{p}=0.002$ and $\mathrm{p}=$ 0.014 , respectively). About $9 \%$ of students reported drinking alcohol in the past month. A notable difference, though not statistically significant, was also observed between males $(6.3 \%)$ and females (3.1\%) with regard to the past-week alcohol use $(\mathrm{p}=0.090)$. Furthermore, about $6 \%$ of male and $2 \%$ of female students reported 
Table 2 Lifetime and current use of alcohol, and the most commonly consumed types by sex, June 2009

\begin{tabular}{|c|c|c|c|c|}
\hline \multirow[b]{2}{*}{ Alcohol use } & \multicolumn{2}{|c|}{ Sex } & \multirow[b]{2}{*}{ Total, n (\%) } & \multirow[b]{2}{*}{ p-value } \\
\hline & Male, $\mathrm{n}(\%)$ & Female, n (\%) & & \\
\hline \multicolumn{5}{|c|}{ Ever drunk alcohol } \\
\hline Yes & $151(35.4)$ & $44(22.4)$ & $195(31.4)$ & 0.001 \\
\hline No & $275(64.6)$ & $152(77.6)$ & $427(68.6)$ & \\
\hline \multicolumn{5}{|c|}{ Drunk alcohol within the last 12 months } \\
\hline Yes & $107(25.1)$ & $28(14.3)$ & $135(21.6)$ & 0.002 \\
\hline No & $319(74.9)$ & $168(85.7)$ & $487(78.4)$ & \\
\hline \multicolumn{5}{|c|}{ Drunk alcohol within the last 30 days } \\
\hline Yes & $48(11.3)$ & $10(5.1)$ & $58(9.3)$ & 0.014 \\
\hline No & $378(88.7)$ & $186(94.6)$ & $564(90.7)$ & \\
\hline \multicolumn{5}{|c|}{ Consumed alcohol within the last 7 days } \\
\hline Yes & $27(6.3)$ & $6(3.1)$ & $33(5.3)$ & 0.090 \\
\hline No & $399(93.7)$ & $190(96.9)$ & $589(94.7)$ & \\
\hline \multicolumn{5}{|c|}{ Currently drinking alcohol } \\
\hline Yes & $24(5.6)$ & $4(2.0)$ & $28(4.5)$ & 0.045 \\
\hline No & $402(94.4)$ & $192(98.0)$ & 594 (95.5) & \\
\hline Total, N (\%) & $426(68.5)$ & $196(31.5)$ & $622(100)$ & \\
\hline
\end{tabular}

that they were current users of alcohol $(p=0.045)$. In general, men were more likely to consume alcohol than females. The types of alcohol most frequently consumed by male students were beer, draft, wine and tela/areqe/ teji, while wine, whisky and beer were the three most commonly consumed alcohols by female students.

Socio-demographic and behavioral correlates assumed to be associated with alcohol use among the study participants were assessed using logistic regression (Table 3). Compared to female, being male was strongly associated with alcohol use within the last 12 months (adjusted OR = $2.14,95 \% \mathrm{CI}=1.22-3.76)$. Orthodox Christianity was also strongly associated with alcohol use in the past year (adjusted OR $=4.67,95 \% \mathrm{CI}=2.05-10.64$ ). The odds of alcohol consumption in the past year among Muslim students were significantly lower compared to students of other religions. Those students whose fathers currently drinks alcohol were more likely to use alcohol in the past year as compared to those students whose fathers did not drink alcohol (adjusted OR $=2.60,95 \% \mathrm{CI}=1.50-4.51$ ). The odds of alcohol use over the past year were 2.47 fold higher among students whose friends currently consume alcohol compared to students whose friends did not (adjusted OR $=2.47,95 \% \mathrm{CI}=1.50-4.08$ ).

Khat use within the past 12 months was strongly and positively associated with alcohol consumption in the past year (adjusted OR $=15.11,95 \% \mathrm{CI}=4.24-53.91$ ) (Table 3). About $77 \%$ of respondents reporting alcohol use in the past year had chewed khat, as opposed to only $23.3 \%$ of those who had not consumed alcohol. Similarly, ever use of cigarette was also significantly associated with alcohol consumption (adjusted OR = 8.65, $95 \% \mathrm{CI}=3.48-21.50)$, $76 \%$ of those who consumed alcohol in the past year ever used cigarette compared to $24 \%$ of those who had not ever used cigarette. The likelihood ratio test suggests an evidence of interaction between friends' use of alcohol and gender $(p=0.026)$ and between parental use of alcohol and gender $(\mathrm{p}=$ 0.003). That means the estimated effect of friends' and parental use of alcohol on the participants use of alcohol varies by gender.

About 14\% (95\% CI = 11.50-17.10) of the participants reported lifetime use of khat (18\% males vs. $6 \%$ females, $\mathrm{p}<0.001$ ) (Table 4). Only $7 \%$ of the participants reported the use of khat within the last 12 months and about $4 \%$ did it in the past week. Only about $2 \%$ of the total respondents reported the current use of khat. Of the total respondents, the proportion of students who had ever smoked and the proportion who reported current cigarette smoking by the time of the study was $9 \%$ and $1.8 \%$, respectively. It was noted that the use of khat and cigarette smoking was reported to be higher among male than female students. The main reasons reported for chewing khat included for effective reading and studying (68\%), for enjoyment (63\%) and to get rid of sleeplessness (43\%). The students also reported that alcohol consumption (75\%) and cigarette smoking (63\%) were the main additional substances used after khat chewing.

Table 5 shows the socio-demographic and behavioral correlates assumed to be associated with khat use among medical students in the past 12 months. Results from a multiple logistic regression analysis indicated that being Muslim was strongly and positively associated with khat use in the past year (adjusted OR $=8.18,95 \%$ $\mathrm{CI}=1.55-43.25$ ), but students who reported business as their parent's main source of income were less likely to 
Table 3 Socio-demographic and behavioral correlates of alcohol use within the last 12 months among undergraduate medical students, June 2009

\begin{tabular}{|c|c|c|c|}
\hline \multirow[b]{2}{*}{ Factors } & \multicolumn{2}{|c|}{$\begin{array}{l}\text { Alcohol use within } \\
\text { the last } 12 \text { months }\end{array}$} & \multirow[b]{2}{*}{$\begin{array}{l}\text { Adjusted* OR } \\
(95 \% \mathrm{Cl})\end{array}$} \\
\hline & No, $n(\%)$ & Yes, n (\%) & \\
\hline \multicolumn{4}{|l|}{ Sex } \\
\hline Female & $168(85.7)$ & $28(14.3)$ & 1.00 (Reference) \\
\hline Male & $319(74.9)$ & $107(25.1)$ & $2.14(1.22,3.76)$ \\
\hline \multicolumn{4}{|l|}{ Age in years } \\
\hline $15-19$ & $178(79.1)$ & $47(20.9)$ & 1.00 (Reference) \\
\hline 20 or more & $309(77.8)$ & $88(22.2)$ & $1.07(0.58,1.98)$ \\
\hline \multicolumn{4}{|l|}{ Religion } \\
\hline Other Christian & $121(91.7)$ & $11(8.3)$ & 1.00 (Reference) \\
\hline Orthodox Christian & $278(71.5)$ & $111(28.5)$ & $4.67(2.05,10.64)$ \\
\hline Muslim & $80(93.0)$ & $6(7.0)$ & $0.20(0.04,0.92)$ \\
\hline Other & $8(53.3)$ & $7(46.7)$ & $13.64(2.58,72.10)$ \\
\hline \multicolumn{4}{|l|}{ Main source of family's income } \\
\hline Government employee & $142(74.7)$ & $48(25.3)$ & 1.00 (Reference) \\
\hline Business & $116(71.6)$ & $46(28.4)$ & $1.78(0.96,3.31)$ \\
\hline Agriculture-based & $121(90.3)$ & $13(9.7)$ & $0.34(0.10,1.12)$ \\
\hline Other & $108(79.4)$ & $28(20.6)$ & $1.12(0.59,2.16)$ \\
\hline \multicolumn{4}{|l|}{ Original background } \\
\hline Rural & $106(85.5)$ & $18(14.5)$ & 1.00 (Reference) \\
\hline Urban & $381(76.5)$ & $117(23.5)$ & $0.94(0.32,2.76)$ \\
\hline \multicolumn{4}{|l|}{ Medical education status } \\
\hline Pre-clinical & $363(81.2)$ & $84(18.8)$ & 1.00 (Reference) \\
\hline Clinical & $124(70.9)$ & $51(29.1)$ & $0.98(0.51,1.90)$ \\
\hline \multicolumn{4}{|l|}{ Father currently drinks alcohol } \\
\hline No & $381(83.7)$ & $74(16.3)$ & 1.00 (Reference) \\
\hline Yes & $106(63.5)$ & $61(36.5)$ & $2.60(1.51,4.51)$ \\
\hline \multicolumn{4}{|l|}{ Mother currently drinks alcohol } \\
\hline No & $442(79.6)$ & $113(20.4)$ & 1.00 (Reference) \\
\hline Yes & $45(67.2)$ & $22(32.8)$ & $0.82(0.40,1.72)$ \\
\hline \multicolumn{4}{|l|}{ Friend currently drinks alcohol } \\
\hline No & $340(88.1)$ & $46(11.9)$ & 1.00 (Reference) \\
\hline Yes & $147(62.3)$ & $89(37.7)$ & $2.47(1.50,4.08)$ \\
\hline \multicolumn{4}{|c|}{ Used khat within the last 12 months } \\
\hline No & $477(82.4)$ & $102(17.6)$ & 1.00 (Reference) \\
\hline Yes & $10(23.3)$ & $33(76.7)$ & $15.11(4.24,53.91)$ \\
\hline \multicolumn{4}{|l|}{ Ever smoked cigarette } \\
\hline No & $474(83.5)$ & $94(16.6)$ & 1.00 (Reference) \\
\hline Yes & $13(24.1)$ & $41(75.9)$ & $8.65(3.48,21.50)$ \\
\hline Total, N (\%) & $487(78.3)$ & $135(21.1)$ & \\
\hline
\end{tabular}

*Adjusted for sex, age, religion (4 levels), income (4 levels), background, education, alcohol intake of friends and parents, khat and cigarette intake.

consume khat than students who reported other source of income for their parents (adjusted OR $=0.27,95 \% \mathrm{CI}$ $=0.08-0.86$ ). Students who reported having a friend who currently chew khat were about eight times more likely to chew khat than those students who reported no such friend (adjusted OR $=8.08,95 \% \mathrm{CI}=2.84-22.98$ ). Likewise, a student who consumed alcohol in the past 12 months had the odds of 17 -fold increase to use khat in the past year (adjusted OR $=16.99,95 \% \mathrm{CI}=4.61$ 62.64). Similarly, ever use of cigarette was strongly associated with khat consumption (adjusted OR $=7.63$, 95\% CI $=$ 2.81-20.71)

The multiple logistic regression model also indicates that various socio-demographic characteristics and other behavioral aspects are associated with lifetime smoking status of medical students (Table 6). Students whose 
Table 4 Respondent's lifetime and current use of khat and cigarette smoking by sex, June 2009

\begin{tabular}{|c|c|c|c|c|}
\hline \multirow[b]{2}{*}{ Khat use and cigarette smoking habit } & \multicolumn{2}{|c|}{ Sex } & \multirow[b]{2}{*}{ Total, n (\%) } & \multirow[b]{2}{*}{$\mathrm{p}$-value } \\
\hline & Male, n (\%) & Female, n (\%) & & \\
\hline \multicolumn{5}{|l|}{ Ever chewed khat } \\
\hline Yes & $77(18.1)$ & $11(5.6)$ & $88(14.1)$ & \\
\hline No & $349(81.9)$ & $185(94.4)$ & $534(85.9)$ & $<0.001$ \\
\hline \multicolumn{5}{|l|}{ Chewed khat within the last 12 months } \\
\hline Yes & $40(9.4)$ & $3(1.5)$ & $43(6.9)$ & \\
\hline No & $386(90.6)$ & $193(98.5)$ & $579(93.1)$ & $<0.001$ \\
\hline \multicolumn{5}{|l|}{ Chewed khat within the last 30 days } \\
\hline Yes & $21(4.9)$ & $2(1.0)$ & $23(3.7)$ & \\
\hline No & $405(95.1)$ & $194(99.0)$ & $599(96.3)$ & 0.016 \\
\hline \multicolumn{5}{|l|}{ Chewed khat within the last 7 days } \\
\hline Yes & $15(3.5)$ & $2(1.0)$ & $17(2.7)$ & \\
\hline No & $411(96.5)$ & $194(99.0)$ & $605(97.3)$ & 0.075 \\
\hline \multicolumn{5}{|l|}{ Currently chewing khat } \\
\hline Yes & $12(2.8)$ & $2(1.0)$ & $14(2.3)$ & \\
\hline No & $414(97.2)$ & $194(99.0)$ & $608(97.7)$ & 0.244 \\
\hline \multicolumn{5}{|l|}{ Ever smoked cigarette } \\
\hline Yes & $45(10.6)$ & $9(4.6)$ & $54(8.7)$ & \\
\hline No & $381(89.4)$ & $187(95.4)$ & $568(91.3)$ & 0.014 \\
\hline \multicolumn{5}{|l|}{ Currently smoking cigarette } \\
\hline Yes & $10(2.3)$ & $1(0.5)$ & $11(1.8)$ & \\
\hline No & $416(97.7)$ & 195 (99.5) & $611(98.2)$ & 0.187 \\
\hline Total, n (\%) & $426(68.5)$ & $196(31.5)$ & 622 & \\
\hline
\end{tabular}

parent's income was based on agriculture reported the odds of 0.15 -fold decrease in lifetime use of cigarette (adjusted OR $=0.12,95 \% \mathrm{CI}=0.01-1.02$ ) compared to others, but it was not statistically significant. Similarly, students with smoker friends were about four times more likely to ever smoke as compared to those whose friends are non-smokers (adjusted $\mathrm{OR}=3.89,95 \% \mathrm{CI}=$ 1.83-8.30). Likewise, study participants who reported the use of alcohol and khat in the last 12 months reported high odds of smoking cigarettes, adjusted OR $=8.56$, $95 \% \mathrm{CI}=3.44-21.35$ and adjusted $\mathrm{OR}=8.28,95 \% \mathrm{CI}=$ 3.24-21.13, respectively. Students whose fathers were reported to be smokers were more likely to smoke, but it was not statistically significant. Sex, age, religion, background and training status of the students were not significantly associated with lifetime smoking. No evidence of interaction was observed between the covariate gender and the main risk factors of friends' use of tobacco and alcohol use.

\section{Discussion}

This study clearly indicates that substance use is becoming a concern among undergraduate medical students. About $22 \%$ of the participants reported alcohol drinking and $7 \%$ used khat in the past 12 months; while lifetime cigarette smoking was reported by $9 \%$ of the students. The prevalence occurs across all years of study, although it is higher among clinical students than pre-clinical ones.

Our reported rate of alcohol consumption among medical students was lower than that reported by other studies in a similar study population. A study in Ethiopia based on a large sample of youth aged between 15 and 24 years showed that about $9 \%$ of in-school youths consumed alcohol either on a weekly or daily basis in Ethiopia [14]. In the USA, a study among a cohort of medical students found that $78 \%$ of them reported drinking alcohol in the past month and 34\% engaged in excessive drinking [24]. A study in Sweden showed that more than $90 \%$ of university students consumed alcohol during the preceding three months and 39\% of males and $20 \%$ of females involved in heavy episodic drinking at least once a week [25].

Studies on khat use among college students in general and medical students in particular are very scanty. Our findings indicate that khat use in the past 12 months and one month was $7 \%$ and $4 \%$, respectively, significantly lower than the $18 \%$ current khat chewing report from four college students in northwest Ethiopia [13]. A study that assessed the association of khat/alcohol use and risky sexual behavior among in-school and out-of-school youth in Ethiopia found that about 9\% of in-school youth reported current intake of khat either weekly or every day [14]. The same study revealed a significant and 
Table 5 Socio-demographic and behavioral correlates of khat use within the last 12 months among undergraduate medical students, June 2009

\begin{tabular}{|c|c|c|c|}
\hline \multirow[t]{2}{*}{ Factors } & \multicolumn{2}{|c|}{$\begin{array}{l}\text { Khat use within } \\
\text { the last } 12 \text { months }\end{array}$} & \multirow[t]{2}{*}{$\begin{array}{l}\text { Adjusted* OR } \\
(95 \% \mathrm{Cl})\end{array}$} \\
\hline & No, $n(\%)$ & Yes, n (\%) & \\
\hline \multicolumn{4}{|l|}{ Sex } \\
\hline Female & $193(98.5)$ & $3(1.5)$ & 1.00 (Reference) \\
\hline Male & $386(90.6)$ & $40(9.4)$ & $3.28(0.80,13.54)$ \\
\hline \multicolumn{4}{|l|}{ Age in years } \\
\hline $15-19$ & $213(94.7)$ & $12(5.3)$ & 1.00 (Reference) \\
\hline 20 or more & $366(92.2)$ & $31(7.8)$ & $0.64(0.18,2.30)$ \\
\hline \multicolumn{4}{|l|}{ Religion } \\
\hline Other Christian & $127(96.2)$ & $5(3.8)$ & 1.00 (Reference) \\
\hline Orthodox Christian & $366(94.1)$ & $23(5.9)$ & $0.62(0.15,2.61)$ \\
\hline Muslim & $74(86.1)$ & $12(14.0)$ & $8.18(1.55,43.25)$ \\
\hline Other & $12(80.0)$ & $3(20.00)$ & $1.42(0.13,13.82)$ \\
\hline \multicolumn{4}{|l|}{ Main source of family's income } \\
\hline Government employee & $172(90.5)$ & $18(9.5)$ & 1.00 (Reference) \\
\hline Business & $149(92.0)$ & $13(8.0)$ & $0.27(0.08,0.86)$ \\
\hline Agriculture-based & $128(95.5)$ & $6(4.5)$ & $0.77(0.09,6.50)$ \\
\hline Other & $130(95.6)$ & $6(4.4)$ & $0.51(0.14,1.87)$ \\
\hline \multicolumn{4}{|l|}{ Medical education status } \\
\hline Pre-clinical & $426(95.3)$ & $21(4.7)$ & 1.00 (Reference) \\
\hline Clinical & $153(87.4)$ & $22(12.6)$ & $2.04(0.61,6.78)$ \\
\hline \multicolumn{4}{|l|}{ Original background } \\
\hline Rural & $116(93.6)$ & $8(6.5)$ & 1.00 (Reference) \\
\hline Urban & $463(93.0)$ & $35(7.0)$ & $0.77(0.11,5.29)$ \\
\hline \multicolumn{4}{|l|}{ Friend currently uses khat } \\
\hline No & $436(96.5)$ & $16(3.5)$ & 1.00 (Reference) \\
\hline Yes & $143(84.1)$ & $27(15.9)$ & $8.08(2.84,22.98)$ \\
\hline \multicolumn{4}{|l|}{ Father currently chews khat } \\
\hline No & $534(93.2)$ & $39(6.8)$ & 1.00 (Reference) \\
\hline Yes & $45(91.8)$ & $4(8.2)$ & $1.75(0.44,7.03)$ \\
\hline \multicolumn{4}{|l|}{ Mother currently chews khat } \\
\hline No & $560(93.1)$ & $42(6.9)$ & 1.00 (Reference) \\
\hline Yes & $19(95.0)$ & $1(5.0)$ & $1.32(0.12,14.74)$ \\
\hline \multicolumn{4}{|c|}{ Consumed alcohol within the last 12 months } \\
\hline No & $477(97.9)$ & $10(2.1)$ & 1.00 (Reference) \\
\hline Yes & $102(75.6)$ & $33(24.4)$ & $16.99(4.61,62.64)$ \\
\hline \multicolumn{4}{|l|}{ Ever smoked cigarette } \\
\hline No & $551(97.0)$ & $17(3.0)$ & 1.00 (Reference) \\
\hline yes & $28(51.9)$ & $26(48.2)$ & $7.63(2.81,20.71)$ \\
\hline Total, N (\%) & $579(93.1)$ & $43(6.9)$ & \\
\hline
\end{tabular}

*Adjusted for sex, age, religion (4 levels), income (4 levels), education, background, khat intake of friends and parents, alcohol and cigarette intake.

positive association between khat/alcohol use and unprotected sex, leading to exacerbation of HIV transmission.

There have been several studies on cigarette smoking among young adults in developed countries, but such studies are scantly in developing countries. In northwest Ethiopia, lifetime and current use of cigarette smoking was reported by $13 \%$ and $8 \%$ of college students, respectively [13]. In a study of in-school rural Zambian adolescents, the prevalence of lifetime cigarette smoking was reported to be $27 \%$ [26], much higher than our findings. Another study conducted among 18-23 year-old college students in India found 14\% prevalence of cigarette smoking [27].

Results from this study provide important insights into the magnitude of substance use and its associated risk factors. The present study found that peer's influence was one of the important factors to influence the 
Table 6 Socio-demographic and behavioral correlates of cigarette smoking among undergraduate medical students, June 2009

\begin{tabular}{|c|c|c|c|}
\hline \multirow[b]{2}{*}{ Factors } & \multicolumn{2}{|c|}{ Ever smoked } & \multirow[b]{2}{*}{$\begin{array}{l}\text { Adjusted* OR } \\
(95 \% \mathrm{Cl})\end{array}$} \\
\hline & No, $n(\%)$ & Yes, n (\%) & \\
\hline \multicolumn{4}{|l|}{ Sex } \\
\hline Female & $187(95.4)$ & $9(4.6)$ & 1.00 (Reference) \\
\hline Male & $381(89.4)$ & $45(10.6)$ & $1.45(0.57,3.67)$ \\
\hline \multicolumn{4}{|l|}{ Age in years } \\
\hline $15-19$ & $209(92.9)$ & $16(7.1)$ & 1.00 (Reference) \\
\hline 20 or more & $359(90.4)$ & $38(9.6)$ & $1.00(0.35,2.64)$ \\
\hline \multicolumn{4}{|l|}{ Religion } \\
\hline Other Christian & $124(93.9)$ & $8(6.1)$ & 1.00 (Reference) \\
\hline Orthodox Christian & $356(91.5)$ & $33(8.5)$ & $0.47(0.15,1.45)$ \\
\hline Muslim & $77(89.3)$ & $9(10.5)$ & $0.90(0.23,3.53)$ \\
\hline Other & $11(73.3)$ & $4(26.7)$ & $3.04(0.34,26.94)$ \\
\hline \multicolumn{4}{|l|}{ Main source of family's income } \\
\hline Government employee & $169(88.9)$ & $21(11.1)$ & 1.00 (Reference) \\
\hline Business & $140(86.4)$ & $22(13.6)$ & $1.15(0.46,2.89)$ \\
\hline Agriculture-based & $131(97.8)$ & $3(2.2)$ & $0.12(0.01,1.02)$ \\
\hline Other & $128(94.1)$ & $8(5.9)$ & $0.61(0.21,1.80)$ \\
\hline \multicolumn{4}{|l|}{ Original background } \\
\hline Rural & $118(95.2)$ & $6(4.8)$ & 1.00 (Reference) \\
\hline Urban & $450(90.4)$ & $48(9.6)$ & $0.69(0.12,4.10)$ \\
\hline \multicolumn{4}{|l|}{ Medical education status } \\
\hline Pre-clinical & $419(93.7)$ & $28(6.3)$ & 1.00 (Reference) \\
\hline Clinical & $149(85.1)$ & $26(14.9)$ & $1.26(0.46,3.45)$ \\
\hline \multicolumn{4}{|l|}{ Friend currently smoking } \\
\hline No & $434(96.0)$ & $18(4.0)$ & 1.00 (Reference) \\
\hline Yes & $18(4.0)$ & $434(96.0)$ & $3.89(1.83,8.30)$ \\
\hline \multicolumn{4}{|l|}{ Father currently smoking } \\
\hline No & $544(91.6)$ & $50(8.4)$ & 1.00 (Reference) \\
\hline Yes & $24(85.7)$ & $4(14.3)$ & $2.57(0.63,10.56)$ \\
\hline \multicolumn{4}{|c|}{ Consumed alcohol within the last 12 months } \\
\hline No & $474(97.3)$ & $13(2.7)$ & 1.00 (Reference) \\
\hline Yes & $94(69.6)$ & $41(30.4)$ & $8.68(3.52,21.45)$ \\
\hline \multicolumn{4}{|c|}{ Used khat within the last 12 months } \\
\hline No & $551(95.2)$ & $28(4.8)$ & 1.00 (Reference) \\
\hline Yes & $17(39.5)$ & $26(60.5)$ & $7.88(3.11,19.95)$ \\
\hline Total, N (\%) & $568(91.3)$ & $54(8.7)$ & \\
\hline
\end{tabular}

${ }^{*}$ Adjusted for sex, age, religion (4 levels), income (4 levels), background, education, smoking status of friends and fathers, alcohol and khat intake.

students to practice substance use. We found that those students who reported friend's use of alcohol, khat and cigarette smoking were more likely to be users of either one or all of the above substances than those students whose friends were non-users. Previous studies also identified that friends' and parental use of substances were strongly associated with the use of substances among adolescents, indicating the influence of peer pressure $[26,28,29]$. Our findings also indicate that students who reported alcohol use of their fathers were more likely to consume alcohol than their counterparts.
Similar findings from other studies also showed that adolescents whose parents smoked were more likely to have smoked [26,30].

Our findings show that being a Muslim was strongly and positively associated with khat use, but inversely related with alcohol use in the last 12 months. In contrast, belonging to Orthodox Christianity was strongly and positively associated with alcohol use. In São Paulo, a study indicated that practicing a religion among university students was found as a protective factor of psychoactive substance use [31]. The same study also found that monthly family 
income was significantly associated with alcohol and drug use. However, the present study reported that family's source of income was not as important as the influence by other factors. In the present study, sex was related with alcohol use and cigarette smoking, yet it was not related with khat use.

The present findings show that students who consume alcohol or use khat are at an increased risk of cigarette smoking. Consistent to our findings, several studies documented an association between cigarette smoking and substance use among adolescents. In Bolivia, cigarette smoking was consistently higher among those who consumed alcohol or other drugs at least once, $24 \%$ of those reporting marijuana use also reported having used tobacco during the preceding 30 days as opposed to only $2 \%$ of those who had not used marijuana [32]. In Pakistan, students whose friends are smokers were more likely to smoke than those whose friends are non-smokers [28].

This study is not free of limitations. First, the study used a descriptive single cross-sectional design that can not establish trends and causality between substance use and potential risk factors. Second, the males are over represented in this sample largely because of disproportionate enrollment of both sexes into the medical school. Small sample sizes, particularly among females and substance users, contributed to wider confidence intervals with low precision. Our sample may also not be representative of the population since only one medical school was purposefully included in the study. Third, the data was collected based on self-report of the students and may be subjected to recall bias and under-reporting of substance use due to social desirability bias. Finally, the lifetime report of cigarette smoking in the current study is not the most sensitive indicator. Despite the limitations, these findings indicate a need to educate medical students regarding substance use and its consequences.

\section{Conclusion}

This study has revealed that the magnitude of substance use among undergraduate medical students was considerable, although not very high, but lower than the findings of other studies that reported for adolescents and young adults. This study also indicated that substance use is significantly associated with friends or parental use of substances. Alcohol consumption or khat use has been significantly associated with cigarette smoking. Understanding factors associated with substance use is the first step for designing and implementing comprehensive anti-substance use interventions that simultaneously prevent multiple risk factors among medical students. The medical profession in turn has an ethical obligation to ensure that its practitioners can discharge their duties and responsibilities for the welfare and safety of the population.

\section{Recommendations}

As our study focuses on undergraduate medical students, the findings would be helpful to initiate effective substance use control programs in medical schools and would also serve as a stimulator to conduct further studies on this topic in Ethiopia.

\section{Acknowledgements}

The study was funded by the Faculty of Medicine and partly supported by the School of Public Health at Addis Ababa University. The authors would like to acknowledge Mr. Abiy Seifu for his assistance in the coordination and supervision of data collection. We gratefully acknowledge medical students who enthusiastically participated in this study for their time and for sharing us their experiences. We also extend our appreciation to Prof. Damen Hailemariam for his support during the planning and implementation of the study.

\section{Author details}

'Department of Epidemiology and Biostatistics, School of Public Health College of Health Sciences, Addis Ababa University, Ethiopia. 'Department of Internal Medicine, School of Medicine, College of Health Sciences, Addis Ababa University, Ethiopia.

\section{Authors' contributions}

WD involved in proposal writing, designed the study and participated in all implementation stages of the project. He analyzed the data, drafted and finalized the write up of the paper. AA conceived the original idea, involved in proposal writing, got funding for the study and participated in all stages of the project implementation and write up of the paper. All authors read and approved the final manuscript.

\section{Competing interests}

The authors declare that they have no competing interests.

Received: 31 March 2011 Accepted: 22 August 2011

Published: 22 August 2011

\section{References}

1. Odejide AO: Status of drug use/abuse in Africa: A review. International Journal of Mental Health 2006, 4:87-102.

2. Volkow ND, Li TK: Drugs and alcohol: Treating and preventing abuse, addiction and their medical consequences. Pharmacology and Therapeutics 2005, 108:3-17.

3. Millikan LE: Alcoholism among health professionals: prevalence and special problems. Clinics in Dermatology 1999, 17:361-363.

4. Kenna GA, Wood MD: The prevalence of alcohol, cigarette and illicit drug use and problems among dentists. J Am Dent Assoc 2005, 136:1023-1032.

5. Kenna GA, Lewis DC: Risk factors for alcohol and other drug use by healthcare professionals. Substance Abuse Treatment, Prevention, and Policy 2008, 3:3.

6. Wechsler H, Rigotti NA, Glendhill-Hoyt J, Lee H: Increased levels of cigarette use among college students - a cause for national concern. JAMA 1998, 280:1673-1678.

7. Shafik M, Shah Z, Saleem A, Siddiqi MT, Shaikh KS, Salahuddin FF, Siwani R, Naqvi H: Perceptions of Pakistani medical students about drugs and alcohol: a questionnaire-based survey. Substance Abuse Treatment, Prevention, and Policy 2006, 1:11-18.

8. Baldwin DC, Hughes PH, Conard SE, Storr CL, Sheehan DV: Substance use among senior medical students: a survey of 23 medical students. JAMA 1991, 265:2074-2078.

9. McCabe SE, Boyd C, Hughes TL, d'Arcy H: Sexual identity and substance use among undergraduate students. Substance Use 2003, 24:77-91.

10. Central Statistical Agency (Ethiopia): The 2007 National Census Preliminary Report for Ethiopia Addis Ababa; 2008.

11. Kassaye M, Sherief TH, Ghimja F, Teklu F: Drug use among school students in Addis Ababa and Butajira. Ethiopian Journal of Health Development 1999, 13:101-106. 
12. Belew M, Kebede D, Kassaye M, Enqusellassie F: The magnitude of khat use and its association with health, nutrition and socio-economic status. Ethiopian Medical Journal 2000, 38:11-26.

13. Kebede Y: Cigarette smoking and khat chewing among college students in North West Ethiopia. Ethiopian Journal of Health Development 2002, 16:9-17.

14. Kebede D, Alem A, Enquselassie F, Berhane F, Abebe Y, Ayele R, Lemma W, Assefa T, Gebremichael T: Khat and alcohol use and risky sex behavior among in-school and out-of-school youth in Ethiopia. BMC Public Health 2005, 5:109.

15. Adugna F, Jira C, Molla T: Khat chewing among Agaro Secondary School students. Ethiopian Medical Journal 1994, 32:161-166.

16. Abebe D, Debella A, Dejene A, Degefa A, Abebe A, Urga K, Ketema L: Khat chewing habit as a possible risk factor for HIV infection: A case-control study. Ethiopian Journal of Health Development 2005, 19:174-181.

17. Seme A, Hailemariam D, Worku A: The association between substance abuse and HIV infection among people visiting HIV counseling and testing centers in Addis Ababa, Ethiopia. Ethiopian Journal of Health Development 2005, 19:116-125.

18. Schinke SP, Fang L, Cole KCA: Substance use among early adolescent girls: risk and protective factors. Journal of Adolescent Health 2008, 43:191-194.

19. Hansson M, Stockfelt L, Urazalin M, Ahlm C, Andersson R: HIV/AIDS awareness and risk behavior among students in Semey, Kazakhstan: a cross-sectional survey. BMC International Health and Human Rights 2008, 2:14.

20. Nasir EF, Astrom AN, David J, Ali RW: HIV and AIDS related knowledge, sources of information, and reported need for further education among dental students in Sudan - a cross sectional study. BMC Public Health 2008, 8:286.

21. Yousafzai AW, Ahmer S, Syed E, Bhutto N, Iqbal S, Siddiqi MN, Zaman M: Well-being of medical students and their awareness on substance misuse: a cross-sectional survey in Pakistan. Annals of General Psychiatry 2009, 8:8.

22. Berhan Y: Medical doctors profile in Ethiopia: production, attrition and retention. In memory of 100-years Ethiopian modern medicine and the new Ethiopian millennium. Ethiopian Medical Journal 2008, 46:1-77.

23. Lemma S: Assessment of risk factors for selected chronic diseases among higher education students in Addis Ababa An MPH thesis submitted to the School of Graduate Studies of Addis Ababa University. School of Public Health, Addis Ababa, Ethiopia; 2007.

24. Frank E, Elon L, Naimi T, Brewer R: Alcohol consumption and alcohol counselling behavior among US medical students: cohort study. British Medical Journal 2008, 337:a2155.

25. Andersson A, Wiréhn A, Ölvander C, Ekman DS, Bendtsen P: Alcohol use among university students in Sweden measured by an electronic screening instrument. BMC Public Health 2009, 9:229.

26. Siziya S, Rudatsikira E, Muula AS, Ntata PRT: Predictors of cigarette smoking among adolescents in rural Zambia: results from a crosssectional study from Chongwe district. Rural and Remote Health 2007, 7:728.

27. Athavale AV, Deshpande SG, Zodpey SP: Social factors in the initiation of cigarette smoking among college students. Regional Health Forum 1997, 2:30-33.

28. Rozi S, Butt ZA, Akhtar S: Correlates of cigarette smoking among male college students in Karachi, Pakistan. BMC Public Health 2007, 7:312

29. Rapeah MY, Munirah Y, Latifah O, Faizah K, Norsimah S, Maryana M, Saub R: Factors influencing smoking behaviors among male adolescents in Kuantan district. Annal Dent Univ Malaya 2008, 15:77-81.

30. Maziak W, Mzayek F: Characterization of the smoking habit among high school students in Syria. European Journal of Epidemiology 2000, 16:1169-1176.

31. Silva LVER, Malbergier A, Stempliuk VA, Andrade AG: Factors associated with drug and alcohol use among university students. Rev Saúde Pública 2006, 40:1-8.

32. Dearden K, Crookston BT, De La Cruz NG, Lindsay GB, Bowden A, Carlston L, Gardner P: Teens in trouble: cigarette use and risky behaviors among private, high school students in La Paz, Bolivia. Pan Am J Public Health 2007, 22:160-168.

\section{Pre-publication history}

The pre-publication history for this paper can be accessed here: http://www.biomedcentral.com/1471-2458/11/660/prepub

doi:10.1186/1471-2458-11-660

Cite this article as: Deressa and Azazh: Substance use and its predictors among undergraduate medical students of Addis Ababa University in Ethiopia. BMC Public Health 2011 11:660.

\section{Submit your next manuscript to BioMed Central and take full advantage of:}

- Convenient online submission

- Thorough peer review

- No space constraints or color figure charges

- Immediate publication on acceptance

- Inclusion in PubMed, CAS, Scopus and Google Scholar

- Research which is freely available for redistribution

Submit your manuscript at www.biomedcentral.com/submit
Biomed Central 